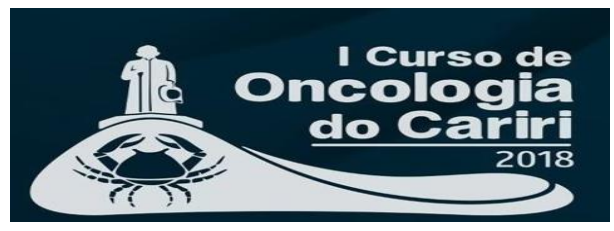

Resumo

\title{
TRATAMENTO DO FIBROXANTOMA ATÍPICO: REVISÃO DE LITERATURA
}

\author{
Bianca de Melo FrançaI, Natalle Wold Gomes da Silva ${ }^{I}$, Jucier Gonçalves Júnior ${ }^{2}$, Samuel Pereira Lima ${ }^{3}$, \\ Gilberto de Alencar Nunes ${ }^{4}$, Roberto Aires Montenegro ${ }^{5}$, Sionara Melo Figueiredo de Carvalho ${ }^{6}$
}

Introdução: Fibroxantoma atípico é um raro tumor de pele que ocorre quase exclusivamente na região da face e do pescoço de idosos devido a exposição solar. Não existem diretrizes baseadas em evidências para o manejo do paciente com Fibroxantoma Atípico, sendo, por vezes, desafiante a definição da terapêutica. Objetivo: Revisão de literatura com a seguinte pergunta norteadora: 'Qual o melhor tratamento para o fibroxantoma atípico?. Método: A busca foi realizada no período de 2000 a 2018 na base de dados Medical Literature Analysis and Retrieval System Online (MEDLINE), utilizando os descritores 'atypical fibroxanthoma' (palavra-chave) e 'treatment' (palavra-chave). Resultados: O Fibroxantoma Atípico possui algumas possibilidades terapêuticas, sendo a ampla ressecção cirúrgica com margens livres o tratamento de escolha mais indicado pelos estudos avaliados. A maioria recomenda uma margem de segurança de 1 a $2 \mathrm{~cm}$ na excisão, e a não dissecção do pescoço é defendida por alguns autores pela baixa incidência de metástases e recorrências desse tumor. Apesar disso, o acompanhamento clínico regular é importante e seu período varia na literatura de 2 a 3 anos, podendo estender-se até 5 anos. Uma alternativa emergente à cirurgia ampla é a cirurgia micrográfica de Mohs, que avalia mais cuidadosamente e completamente a margem cirúrgica, preservando mais tecido saudável e estando associada a menores índices de recorrência nos estudos avaliados. A radioterapia adjuvante pode ser indicada em casos irressecáveis ou não completamente ressecáveis, assim como na presença de fatores de mal prognóstico, como alto índice mitótico, invasão de tecido subcutâneo, radiação prévia, necrose tumoral e ausência de margens cirúrgicas livres. Essa modalidade pode evitar múltiplas excisões, enxertos cutâneos e cuidados com feridas em pacientes idosos. Já o papel da quimioterapia adjuvante é controverso e está indicado principalmente em casos de metástase. Conclusão: A cirurgia ainda é a melhor opção terapêutica para o Fibroxantoma Atípico, sendo a excisão ampla com margens livres a mais utilizada. A cirurgia micrográfica de Mohs é menos mutiladora e possui níveis de recorrência menores, mas a escassez de estudos não permite sua indicação como primeira escolha. A radioterapia adjuvante é utilizada principalmente em casos irressecáveis, não completamente ressecáveis e com fatores de mal prognóstico. A quimioterapia, apesar de controversa, é geralmente indicada em casos de metástase.

Palavras-chave: Fibroxantoma atípico; Tratamento; Revisão de Literatura

\footnotetext{
${ }^{1}$ Graduanda de Medicina da Universidade Federal do Cariri;

${ }^{2}$ Médico formado na Universidade Federal do Cariri;

${ }^{3}$ Especialista em cirurgia de cabeça e pescoço do Centro de Oncologia do Cariri- Hospital Maternidade São Vicente de Paulo;

${ }^{4}$ Especialista em anatomia patológica do Centro de Oncologia do Cariri - Hospital Maternidade São Vicente de Paulo;

${ }^{5}$ Especialista em radioterapia do Centro de Oncologia do Cariri - Hospital Maternidade São Vicente de Paulo;

${ }^{6}$ Mestre em Ciências da Saúde da Universidade Federal do Cariri.

Autor correspondente: bianca.melos2@gmail.com.
} 